\title{
Identifying and Ranking Environmental Risks of Oil and Gas Projects Using the VIKOR Method for Multi-Criteria Decision Making
}

\author{
SasanAryaee ${ }^{1}$, Mehdi Ravanshadnia*2 \\ ${ }^{1}$ M.Sc, Department of civil engineering, science and research branch, Islamic Azad University, Tehran, Iran , phone: +61- \\ 416-655528; e-mail: aryaeesasan@ gmail.com \\ ${ }^{2} \mathrm{PhD}$, Department of civil engineering, science and research branch, Islamic Azad University, Tehran, Iran , phone: \\ +989121071695; e-mail: ravanshadnia@gmail.com
}

\begin{abstract}
Naturally, any activity is associated with risk, and humans have understood this concept from very long times ago and seek to identify its factors and sources. On the one hand, proper risk management can cause problems such as delays and unforeseen costs in the development projects, temporary or permanent loss of services, getting lost or information theft, complexity and limitations in processes, unreliable information caused by rework, holes in the systems and many such problems.In the present study, a model has been presented to rank the environmental risks of oil and gas projects. The statistical population of the study consists of all executives active in the oil and gas fields that the statistical sample is selected randomly. In the framework of the proposed method, environmental risks of oil and gas projects were first extracted, then a questionnaire based on these indicators was designed based on Likert scale and distributed among the statistical sample. After assessing the validity and reliability of the questionnaire, environmental risks of oil and gas projects were ranked using the VIKOR method of multiple-criteria decision-making.The results showed that the best options for HSE planning of oil and gas projects that caused the reduction of risks and personal injury and casualties and less than other options is costly for the project and it will add less time to the duration of implementing the project is the entering of dye to the environment when painting the generator pond and the presence of the rigger near the crane.
\end{abstract}

Keywords: Ranking, Multi-criteria Decision Making, Oil and Gas Projects, HSE Management, Environmental Risks.

\section{Introduction}

Organizations face with billions of dollars of human, equipment, and reputational damages each year due to the accidents and illnesses caused by work and the elimination of environmental pollutions from their activities. Statistics show that there are nearly three million industrial units operating in the country that more than 400,000 industrial and mining units have allocated a significant share of these activities. The number of employees in these units is over two and a half million employees and the share of value added of industrial, mining units in the total national economy is about $25 \%$. Manufacturing, industrial units, which are the driving force of the country's economy, play a significant role in the national economy in terms of employment, production, value added, exports and promotion of national productivity [1].

These damages are considered the important barriers of development and therefore, it is reasonable that the management of organizations should consider the management on the occupational health, safety and environmental aspects regarding other aspects of management such as quality, economic and financial, technology, production and the like, because improvement in the overall performance of the organization is not possible without investigating these aspects [2].

Risk assessment is the process of qualitative and quantitative analysis of the risk potentials and actual coefficient of potential risks arising from project implementation as well as the sensitivity or vulnerability of the peripheral environment. In other words, it can be stated that in risk assessment, the sensitivities of human societies as acceptors of effects are examined in the analysis. Therefore, it is necessary to study and analyze different aspects of risk, nature and types of risks arising from activities in the fields of safety, occupational health and the environment [3].

In this study, VIKOR method was used to rank and evaluate environmental risks in oil and gas projects. VIKOR method is a compensatory multi-criteria decision making method developed by Opricovic\&Tzeng. Thus, according to the importance of risk management and ranking of environmental risks in oil and gas projects and considering the accuracy of multi-criteria 
decision-making methods, in the present study, ranking the risks in the projects of oil and gas have been investigated using the VIKOR technique[11].

\section{Environmental Risk Management}

Project risk is the uncertain possible events or situations that impact the project's objectives as negative or positive consequences. Each of these events or situations has distinct causes and identifiable results and consequences. The consequences of these events are directly effective in the time, cost, quality and scope of the project[4].

By the advancement of technology and the increasing use of machinery, the dangers and potential accidents in industrial environments have also increased. In different industries, operating units are dealt with high temperature and pressure; as a result, there is the possibility of accidents. The oil, gas and petrochemical industries, as one of the largest sources of environmental pollutants, have different type and level of pollution based on the type of inputs, the process steps and the output product. The various stages of oil exploration, extraction and processing, as well as its downstream industries, and the activities of refineries and the exploitation of petrochemicals in the country each have different and varying environmental impacts that soil, air, water (including surface and groundwater), creatures, plants, trees and even humans are affected by these effects [6].

There are also other environmental concerns such as earth warming, ozone depletion, water pollution and species extinction. Given that the oil, gas and petrochemical storage tanks are considered the important infrastructure and also because of the pervasive environmental hazards, this industry has been always considered by the environmental and safety experts [5].

The oil, gas and petrochemical industries are one of the most important industrial facilities, which are always at risk of releasing toxic substances, fires and explosions, among which the fire is the most common and explosion due to the death rate is the most important risk in the storage tanks. Also, due to the presence of semi-volatile hydrocarbon pollutants and volatile organic compounds in the refinery environment, these pollutants have extensive activity in the unsaturated soil environment and they can contaminate the soil around the reservoirs. Risk assessment is a systematic and organized approach to identify risks and ranking them for decision-making, prevention and reducing risk and reaching it to an acceptable extent [7].

\section{Literature Review}

Mohammad Beigi in their research, have identified and ranked risk management in reducing the costs of implementing construction projects in the oil and gas industry. In their view, the risks may continuously affect the stability of project throughout the oil and gas project. Therefore, it is extremely important that all risks - especially in developing countries - to be identified prior to the start of the project. One of the most important tasks for a successful performance in the oil and gas projects is to estimate and moderate risks prior to the start of the project, the specific risks of the project can be controlled by the private sector. These risks can be classified into development, construction and implementation risks. In the first part, the development risks include deficiencies in submitting a request for project proposal, delay in planning and approval of forms in the economic, environmental or technological evaluation, or disqualification of the project by the entity having the power to determine the rejection or acceptance of competency. Among these risks, at this stage, the risk of proposing price may be most important, the importance is due to the reduction of investment costs in various studies and the preparation of the proposed package.

Ahmadi and Jamalihave used AHP and TOPSIS multi-criteria decision making methods in fuzzy environment to identify and rank the hazards of oil projects based on PMBOK standard. They believe that risk in projects can have a significant impact on short-term performance as well as long-term negative impact on financial performance of the organization, thus risk management is essential to reduce failures caused by various risks such as uncertain economic cycles, uncertain customer demand and unforeseeable natural and human disasters, etc. Therefore, it is important to have a list of important risks in the field of oil and gas projects as well as prioritizing and determining theirimportance. Therefore, in their research, they identify the technical engineering risks in south Tehran using risk identification and grouping methods in the PMBOK standard and then determine the weight of cost, time, quality and 
range criteria using the fuzzy analytic hierarchy process and finally, prioritize risks using TOPSIS method in general and in each group[12].

Amiriin his research has used the CPM network and the TOPSIS method in fuzzy mode to rank project's activities risk. risk. This article uses two criteria of cost and time to rank activities. Since the duration and cost of the activities are not certain, these two criteria are considered fuzzy. The time criterion is considered as the degree of criticality obtained from the the fuzzy CPM network in the method. Since, according to the objectives and conditions of each project, the importance of of cost and time is different, these two criteria are allocated weight, and then the activities were ranked according to their risk using Fuzzy TOPSIS method.

Bideyhas examined the risk management of construction projects by applying contractual considerations. In this paper, the methods that contractually cause to the creation of proper risk management during a project implementation are divided and explained into four categories: creating a winning system in contract, using participatory systems, selecting the appropriate system of project execution, obtaining feedback from executed contracts, and applying in new contracts. The results show that applying the above methods in regulating contracts of development projects will play an important role in risk reduction and litigation management.

Khazaini and Afsharhave identified the project risks and proposed a specific structure for classifying them in a study utilizing the experiences gained from projects in the world and studies in this field. They believe that it can hope for the success of the project only if the risks to be identified and properly allocated and prepared to manage them. Identifying the risks at each stage is essential for gaining readiness for the proper control and management of the risks, as well as assigning and determining responsibility for each of the project agents in the project agreement.

Asbes in their paper have presented a new approach to project control under uncertainty considering return to the basic principles of management. Their model includes integration in earned value methodology and risk management. They used the data from three case studies to evaluate the model. The results of the model implementation on the sample problems have been shown that the proposed model has the required validity and it has a significant impact on increasing quality, cost reduction and time and it provides optimal scheduling for the project.

Teller in their paper examined empirical research on how risk management affects the project portfolio success. This study examines how portfolios risk management affects the project success. Using a sample of 176 companies, this study provides evidence that identifying portfolio risk, adaptation of portfolio risk management process and risk management culture directly influence risk transparency. Given that the risk prevention, risk monitoring, and the integration of risk management within a portfolio management project, is directly related to the capacity coping with risk. The findings also show that both risk transparency and the capacity coping with risk have a direct impact on the project success. However, the results do not approve the hypothesis that risk transparency and the capacity coping with risk have a complementary effect on success. The concepts for researchers and project managers are discussed.

Fuzhou and Hang Yan have assessed the financing risk of construction engineering projects. This paper analyzes the financing model of construction engineering projects to identify five important factors that influence financial risk and this model is used to compile a questionnaire report. This model demands the standardization process and model form for postinvestment data and obtains the combined value of the risk and then judges the project's risk level, which provides key benefits to the construction engineering project that relates to risk management departments.

\section{Research Method}

Multi-criteria decision-making methods that have been considered by the researchers in the last 30 years have been used from multi-criteria of measurement rather than optimality measurement criteria. Multi-criteria decision making models are divided into two main categories: multi-objective diffusion models and multi-attribute decision making. Generally, multiobjective models are used to design and multi-objective models are used to select the best option. The main difference between multi-objective decision models and multi-criteria decision models is that the former are defined in the continuous decision space and the latter defined in discrete decision space [9].

The purpose of multi-attribute decision-making models is to select (evaluate) the best option among the finite number of options (sometimes instead of option, ssynonyms of strategy are used, etc.). In addition to the options, there are several 
indices that the decision maker must specify in his or her own issues. These indices are examined in relation to each option [10].

The output of multi-attribute decision-making models will be an option that provides the most preferred value or of any existing attribute. Note also that access to the optimal option is impossible in most cases, but choosing the most appropriate option will be relatively feasible in any case. As a result, the output of multi-attribute decision making makes the order and priority of the options available in the decision matrix available relative to each other [14].

In this study, VIKOR method was used to rank and evaluate environmental risks in oil and gas projects. This method can provide a maximum value of group desirability for the majority and a minimum value of single effect for the opposition.

For conducting this method, we first normalize the initial decision matrix. Next, we determine the positive ideal answer (the highest priority option) and the negative ideal answer (the lowest priority option), then we calculate the distance of the options from the ideal solutions and calculate the amount of VIKOR and then rank and decide on the options [8].

VIKOR, a multi-criteria decision-making method to solve a discrete decision problem with inappropriate metrics (different units of measurement) and contradictory has been developed by Opricovic\&Tzeng. VIKOR is derived from the Serbian name, which means Multi-Criteria Optimization \& Compromise Solution. This model has been developed since 1984 based on a collective agreement method with conflicting criteria and it is generally used to solve discrete problems Considering the use of the VIKOR method in this study, it is necessary to consider the criteria. The criteria that are investigated in assessing and ranking the environmental risks of oil and gas projects are [13]:

- Probability of risk occurrence

- Impact on project cost

- Impact on project time

- Impact on personal injury and causalities.

Also, based on the literature review, the most important environmental risks of oil and gas projects are:

1. Collision of machinery and equipment with oil or gas pipeline during excavation

2. Rigger's presence near the crane

3.Collision of machinery and equipment with underground electrical installations during excavation

4.Injection of acidic and chemical substances

5.Radiation during radiography

6. Contact with molten bitumen and breathing smoke and fumes caused by bitumen

7. Contact with UV during welding

8. Oil spill during flushing

9.Enteringdye into the environment when painting a generator pool

10. Launching welding sparks [15].

In this research, first, using the library method and referring to specialized Persian and Latin books and journals and valid scientific sites, the data and basic information needed were collected to formulate the theoretical foundations of the research and then the information needed to rank the ten risks identified was collected using a researcher-made questionnaire

[16].

In MADM techniques, the objective is to evaluate the options based on the criteria and to select the optimal option. In this model, the criteria are not weighted but the weight of the criteria is obtained from other methods and used as input. 
Table 1. Weight of options

\begin{tabular}{|c|c|c|}
\hline Weight & Symbol & Scale \\
\hline 1 & VL & Very low \\
\hline 3,2 & L & Low \\
\hline 4,3 & ML & Relatively low \\
\hline 4,5 & M & Medium \\
\hline 5,6 & MH & Relatively high \\
\hline $6,7,8$ & H & High \\
\hline 9 & VH & Very high \\
\hline
\end{tabular}

The evaluation of options is based on criteria by the decision matrix. There are always several options in this model that are evaluated based on multi-criteria independently and ultimately, the options are ranked by value. The statistical population of the study includes all managers active in the fields of oil and gas that the statistical sample is selected randomly. Different methods are used to determine sample size in research. Cochran formula was used to determine sample size in this study. Thus, considering 250 for the statistical population, the minimum sample size is 150 persons [17].

Content validity and face validity were used to determine the validity of the questionnaire. Waltz and Bausellmethod was used to investigate the content validity index. In this way, the experts identified the "relevance", "clarity" and "simplicity" of each question on a scale. The minimum acceptable value for this index was 0.79 . In the present questionnaire, all the questions obtained this value and therefore the content validity of the questionnaire was confirmed.

To investigate the face validity, the opinions of the target sample group or research respondents are used, and this part of the validity of the test does not require the opinions of experts. To assess the impact scores, participants were first asked to specify the importance of each question on a five-point Likert scale ranging from 1 (not at all important) to 5 (quite important). To accept the face validity of each question, its impact score must not be less than 1.5 , and only questions are acceptable in terms of face validity that have a score above 1.5 that all questions in the present study have an impact score greater than this value. Therefore, the face validity of the research questionnaire was confirmed.

Cronbach's alpha method was used to measure reliability. The Cronbach's alpha method is used to measure the internal reliability of an index's items, mainly for questionnaires that its questions are designed in spectrum and its answers are multioption. The Cronbach's alpha for the present questionnaire is 0.782 , which is greater than 0.7 and confirms the reliability of the questionnaire.

\section{Data Analysis}

This section ranks the risks identified using the VIKOR method.

1) Initial Decision Matrix Formation:

The initial decision matrix is obtained from the geometric mean of the respondents' comments as described in Table 2 . 
Table 2. VIKOR's initial decision matrix

\begin{tabular}{|c|c|c|c|c|}
\hline $\begin{array}{c}\text { Impact on } \\
\text { personal } \\
\text { injuries and } \\
\text { causalities }\end{array}$ & $\begin{array}{c}\text { Impact } \\
\text { of the } \\
\text { time of } \\
\text { project }\end{array}$ & $\begin{array}{c}\text { Impact } \\
\text { of the } \\
\text { cost of } \\
\text { project }\end{array}$ & $\begin{array}{c}\text { Probability } \\
\text { of } \\
\text { occurrence }\end{array}$ & Risk \\
\hline 9 & 3 & 2 & 8 & F1 \\
\hline 7 & 4 & 3 & 8 & F2 \\
\hline 5 & 2 & 2 & 7 & F3 \\
\hline 3 & 1 & 2 & 2 & F4 \\
\hline 5 & 2 & 3 & 5 & F5 \\
\hline 2 & 1 & 2 & 1 & F6 \\
\hline 1 & 5 & 4 & 2 & F7 \\
\hline 8 & 2 & 5 & 2 & F8 \\
\hline 8 & 5 & 6 & 3 & F9 \\
\hline 4 & 2 & 2 & 2 & F10 \\
\hline
\end{tabular}

2) Normalizing or non-scaling the initial decision matrix: Using the linear normalization formula, all of the matrix values are multiplied by 2 and the sum of each column is summed and then the square root is obtained and finally, each value is divided by the obtained square root. The results of this step can be seen in Table 3.

Table 3. Normal initial decision matrix

\begin{tabular}{|c|c|c|c|c|}
\hline $\begin{array}{c}\text { Impact on } \\
\text { personal } \\
\text { injury and } \\
\text { causalities }\end{array}$ & $\begin{array}{c}\text { Impact of } \\
\text { the time of } \\
\text { project }\end{array}$ & $\begin{array}{c}\text { Impact of } \\
\text { the cost of } \\
\text { project }\end{array}$ & $\begin{array}{c}\text { Probability } \\
\text { of } \\
\text { occurrence }\end{array}$ & Risk \\
\hline 0.489535464 & 0.311085508 & 0.186500962 & 0.529812943 & F1 \\
\hline 0.380749805 & 0.414780678 & 0.279751442 & 0.529812943 & F2 \\
\hline 0.271964147 & 0.207390339 & 0.186500962 & 0.463586325 & F3 \\
\hline 0.163178488 & 0.103695169 & 0.186500962 & 0.132453236 & F4 \\
\hline 0.271964147 & 0.207390339 & 0.279751442 & 0.331133089 & F5 \\
\hline 0.108785659 & 0.103695169 & 0.186500962 & 0.066226618 & F6 \\
\hline 0.054392829 & 0.518475847 & 0.373001923 & 0.132453236 & F7 \\
\hline 0.435142635 & 0.207390339 & 0.466252404 & 0.132453236 & F8 \\
\hline 0.435142635 & 0.518475847 & 0.559502885 & 0.198679854 & F9 \\
\hline 0.217571317 & 0.207390339 & 0.186500962 & 0.132453236 & F10 \\
\hline
\end{tabular}
3)
Determining
the
ideal
positive
and
negative
points:

At this point, the best and worst value of each option is determined. These values are visible in Table 4 .

Table 4. Ideal Positive and Negative Point

\begin{tabular}{|c|c|c|c|c|}
\hline $\begin{array}{c}\text { Impact on personal injuries and } \\
\text { causalities }\end{array}$ & $\begin{array}{c}\text { Impact of the time of } \\
\text { project }\end{array}$ & $\begin{array}{c}\text { Impact of the cost of } \\
\text { project }\end{array}$ & $\begin{array}{c}\text { Probability of } \\
\text { occurrence }\end{array}$ & Option \\
\hline 0.489535464 & 0.518475847 & 0.559502885 & 0.529812943 & Positive ideal \\
\hline 0.054392829 & 0.103695169 & 0.186500962 & 0.066226618 & Negative ideal \\
\hline
\end{tabular}


4) DeterminingS and R:

Using the relative distance formula, the $\mathrm{i}$-option of the ideal point is equal to $\mathrm{S}$ and the maximum inconvenience of the i-option of distance from the ideal point is calculated equal to $\mathrm{R}$. These values are listed in Table 5.

Table 5. Determining the index of benefit and regret

\begin{tabular}{|c|c|c|}
\hline Regret (R) & Benefit (S) & Risk \\
\hline 1.5 & 1 & F1 \\
\hline 1.25 & 0.75 & F2 \\
\hline 2.392857143 & 1 & F3 \\
\hline 3.607142857 & 1 & F4 \\
\hline 2.428571429 & 0.75 & F5 \\
\hline 3.875 & 1 & F6 \\
\hline 2.357142857 & 1 & F7 \\
\hline 1.982142857 & 0.857142857 & F8 \\
\hline 0.839285714 & 0.714285714 & F9 \\
\hline 3.232142857 & 1 & F10 \\
\hline
\end{tabular}

5) DeterminingQ value and ranking of executive risks:

By determining $\mathrm{Q}$, the options are sorted and ranked in descending order. The best rank is for an option with the lowest Q. The values of this index are visible in Table 6.

Table 6. Determining VIKOR Index and Ranking of Options

\begin{tabular}{|l|l|l|}
\hline VIKOR index $(\mathrm{Q})$ & Risk & Rank \\
\hline 0.608823529 & F1 & 5 \\
\hline 0.130147059 & F2 & 2 \\
\hline 0.755882353 & F3 & 7 \\
\hline 0.955882353 & F4 & 9 \\
\hline 0.324264706 & F5 & 3 \\
\hline 1 & F6 & 10 \\
\hline 0.75 & F7 & 6 \\
\hline 0.438235294 & F8 & 4 \\
\hline 0 & F9 & 1 \\
\hline 0.894117647 & F10 & 8 \\
\hline
\end{tabular}

6) Two final conditions of the VIKOR technique:

Condition One: Establishing the following equation:

$$
Q\left(a^{\prime \prime}\right)-Q\left(a^{\prime}\right) \geq D Q
$$

Where $a^{\prime}$ is the first option and $a^{\prime \prime}$ is the next option, and $D Q=\frac{1}{n-1}$ andnindicates the number of options. This value is:

$0.130147059-0 \geq \frac{1}{10-1}$

$0.130147059 \geq 0.111111111$

- The first condition is established. 
Condition two: The option that has the lowest value of the VIKOR index (ie F9) must have at S or R the least value. This is established for F9 and in both cases, S and R has the lowest value.

- The second condition is established.

As such, the rankings made by the VIKOR method are acceptable and can be interpreted.

The final ranking obtained can be seen in Table 7:

Table 7. Environmental risk ranking of oil and gas projects

\begin{tabular}{|l|c|}
\hline Risk & Rank \\
\hline Enteringdye into the environment when painting a generator pool & 1 \\
\hline Rigger's presence near the crane & 2 \\
\hline Radiation during radiography & 3 \\
\hline Oil spill during flushing & 4 \\
\hline Collision of machinery and equipment with oil or gas pipeline during excavation & 5 \\
\hline Contact with UV during welding & 6 \\
\hline $\begin{array}{l}\text { Collision of machinery and equipment with underground electrical installations during } \\
\text { excavation }\end{array}$ & 7 \\
\hline Launching welding sparks. & 8 \\
\hline Injection of acidic and chemical substances & 9 \\
\hline Contact with molten bitumen and breathing smoke and fumes caused by bitumen & 10 \\
\hline
\end{tabular}

\section{Conclusion}

Project's Risk Management is one of the major topics of project management that involves planning, organizing, monitoring and controlling all aspects of a project, including risk identification, measurement, risk response development and risk response control.

It was concluded from the results in VIKOR technique that the options that reduce the probability of occurring risks and personal injuries and causalities more than other options and less than the other options are costly for the project and will add less time to the project is the entering of dye to the environment when painting the generator pond and the presence of a rigger near the crane.

To reduce the harmful effects of these two risks, it is recommended to use safety signs. Safety signs are one of the cheapest and easiest ways to control and prevent risks. There are many standards in the world for producing safety signs, each of these standards has its own advantages and disadvantages. Based on relevant criteria, all hazardous items in workplace and safety training tips such as packages containing radionuclides, devices used to transport radionuclides, radiation-producing sources, and areas containing radionuclides, chemicals, electrical, petroleum and gas fuels, work at height and paths must be specified and adhere to the principles of installation of warning safety signs.

In large industries, it is almost impossible all employees to be familiar with all the dangers and all the places due to the experience. On the other hand, workers and employees may move from one unit to another and do not have the enough opportunity to identify their workplace risks. Installing safety signs in the workplace can expedite the process of introducing risks to employees. It is recommended that health and safety authorities identify hazards and unsafe conditions and install appropriate safety signs.

National Safety Association has cited the fault in correct informing hazards by safety boards as the third most common factor in investigating accidents. Other studies have shown that the use of warning signs and labels is one of the best ways to control accidents. Therefore, the use of safety signs to improve employees' behavior is considered. Safety signs as an indicator of danger, hazardous conditions or consequences of danger points safety precautions and recommendations to persons who commit unsafe and dangerous behaviors and show the ways to avoid them. 
Safety signboard information plays an important role in promoting industrial safety, controlling the behavior of engineers and workers in the form of guidelines related to hazards and industry injuries. Now, the equipment can be effective, effective, if they are designed in accordance with ergonomic principles and based on the human factors, otherwise the problem in the information processing process will in turn increase the likelihood of unsafe behavior by the worker. In total, it is important to note that signs must be designed so that they are clearly visible, recognizable, and understandable, understandable, and they may result in death or serious injury if they are not fully and effectively showed.

\section{References}

[1] Amiri, Maghsoud (2013). Providing a Method for Ranking Project Activity Risk Using CPM Network and TOPSIS Method in Fuzzy Mode, Industrial Management Perspective, No. 10, pp. 183- 169.

[2] BarkhordariAhmadi, Mahnaz.,Jamali, Ebrahim. (2017). Hazard Identification of Oil Projects Based on PMBOK Standard and Their Ranking by AHP and TOPSIS Approach in Fuzzy Environment, Technology Growth, Volume 13, Number $50,50-41$.

[3] Alborz, ER (2004). Insurance Risk Management and Offshore Facility, Journal of Health, Safety and Environment Management System, Nefa Offshore Iran Company, No. 10, 8-9.

[4] Bidi, Abbas. (2008). Risk Management of Civil Projects by Applying Contractual Considerations, Fourth International Project Management Conference.Ariana Research Group.

[5] Khazaini, Garshasb.,Afshar, Abbas. (2005). Risk sharing, the basis of risk management in BOT projects, 4th International Conference of Industrial Engineering.

[6] Dana, Toraj. (2004). A Look at the Position of the Environment in Governmental Organizations, Green Organization, Petro Pars Journal, Issue 7, 28-29.

[7] Roayai, AS. (2005). Stablishing an Integrated Health and Environmental Safety System at National Iranian Oil Company, HSE National Conference on Safety Engineering and Management, Sharif University of Technology.

[8] Mohammad Beigi, Majid., Lori, Alireza., Talouri, Abdul Rasoul. (2018). Identifying and Ranking Risk Management in Reducing Costs of Implementing Construction Projects in the Oil and Gas Industry, Fourth National Conference on Urban Planning, Architecture, Civil and Environment, Shirvan, Research Institute of RahjouyanPayaShahrAtrak

[9] Momeni, Mansour. (2006). Recent Issues in Operations Research, University of Tehran School of Management, Tehran.

[10]Wazdani, Soghra, SabzGhobaiy, Gholamreza. Dashti, Sulmaz, Cheraghi, Mitra. Alizadeh, Reza. Hemmati, Azam. 2018. Application of FMEA Model for Environmental, Safety and Health Risks Assessment of Parsian Gas Refinery Storage Tanks in 2016. Journal of Rafsanjan University of Medical Sciences. Issue 17, Volume 4, pp. 345-358

[11] Acebes, F., Pajares, J., Manuel Galán, J., López-Paredes, A. (2014). A new approach for project control under uncertainty.Going back to the basics, International Journal of Project Management, 32, 423-434.

[12] Doumpos, M., \&Grigoroudis, E. (2013). Multi-criteria Decision Aid and Artificial Intelligence. Whiley (UK).

[13] Fu-zhou. L., Hong-yuan, G. (2011).The risk assessment model of BT construction engineering project financing, Systems Engineering Procedia, 1, 169-173.

[14] Huang, J. J., Tzeng, G. H., \& Liu, H. H. (2009). A revised VIKOR model for multiple criteria decision making-The perspective of regret theory. In International Conference on Multiple Criteria Decision Making (pp. 761-768).Springer, Berlin, Heidelberg.

[15] Liu, H., \& Yan, T. (2007, August). Bidding-evaluation of construction projects based on VIKOR method.In 2007 IEEE International Conference on Automation and Logistics (pp. 1778-1782).IEEE.

[16] Shaluf I, Abdullah S. Floating roof storage tank boilover.J of Preve in the Process Indus 2010; 3: 1- 7.

[17] Teller, J., Unger, B. N., Kock, A., \&Gemünden, H. G. (2012). Formalization of project portfolio management: The moderating role of project portfolio complexity. International Journal of Project Management, 30(5), 596-607. 